\title{
PENGARUH KINERJA KUALITAS PELAYANAN MELALUI SEVEN ROMANCING MOMENTS TERHADAP PEMBELIAN ULANG PADA RESTORAN HOKA HOKA BENTO CABANG SETIABUDI BANDUNG
}

\author{
Lili Adi Wibowo \\ Esti Fitria
}

\begin{abstract}
Abstrak
Seiring dengan tingkat ekspektasi dan persepsi pelanggan yang semakin meningkat serta tingginya intensitas persaingan bisnis restoran, maka Hoka Hoka Bento tidak bisa hanya mengandalkan variasi menu atau sistem service yang biasa saja. Hal tersebut dikarenakan semua restoran jepang memiliki produk dan fasilitas fisik yang tidak jauh berbeda. Setiap restoran dituntut untuk menggunakan aspek unique service sebagai alat bersaing yang dapat diandalkan. Menyadari kondisi tersebut, Hoka Hoka Bento menerapkan program layanan seven romancing moments. Tujuan penelitian ini adalah untuk memperoleh temuan mengenai kualitas pelayanan melalui seven romancing moments dan pembelian ulang pada restoran Hoka Hoka Bento cabang Setiabudi Bandung, serta untuk menjelaskan pengaruh kinerja kualitas pelayanan melalui seven romancing moments terhadap pembelian ulang pada restoran Hoka Hoka Bento cabang Setiabudi Bandung.

Metode penelitian yang digunakan adalah metode deskriptif dan explanatory survey dengan pengembangan penelitian bersifat cross sectional method. Populasi penelitian berjumlah 7.210 pengunjung Hoka-Hoka Bento Cabang Setiabudi yang merupakan jumlah rata-rata kunjungan perbulan (customer dine in). Berdasarkan teknik penarikan sampel secara simple random sampling dan menggunakan rumus Slovin diperoleh sampel sebesar 73 sampel, namun untuk meningkatkan keakuratan maka jumlah sampel yang diteliti ditambah sehingga berjumlah 100 sampel. Data yang digunakan adalah data primer dan sekunder dengan teknik pengumpulan data melalui wawancara, observasi, penyebaran kuesioner dan studi literatur. Pengujian hipotesis dilakukan dengan menggunakan path analysis dengan bantuan software komputer SPSS.

Hasil penelitian menunjukkan program layanan seven romancing moments yang terdiri dari irasshaimase mobile service, pembayaran di kasir, greeting customer di loby, menawarkan dan mengantarkan menu, take away, serta arigato gozaimatsu, memiliki kategori yang tinggi, dengan dimensi seven romancing moments yang paling tinggi pengaruhnya terhadap pembelian ialah mobile service. Pembelian ulang pada restoran Hoka Hoka Bento cabang Setiabudi Bandung secara umum berkategori cukup dengan dimensi pembelian ulang yang paling tinggi karena kepuasan terhadap pelayanan. Hal tersebut menunjukkan bahwa pelaksanaan program layanan seven romancing moments yang dilakukan Hoka Hoka Bento melalui Irasshaimase mobile service, pembayaran di kasir, greeting customer di loby, menawarkan dan mengantarkan menu, take away, serta arigato gozaimatsu mampu mempengaruhi pembelian ulang pada restoran Hoka Hoka Bento cabang Setiabudi Bandung.
\end{abstract}

Kata Kunci: Kualitas Pelayanan dan Pembelian Ulang

\section{PENDAHULUAN}

Era globalisasi menjanjikan suatu peluang dan tantangan bisnis baru dalam berbagai sektor industri di Indonesia. Salah satu industri yang berkembang adalah restoran fast food. Restoran fast food merupakan pilihan yang tepat di tengah situasi perekonomian dan perkembangan jumlah penduduk Indonesia. Pertumbuhan restoran fast food di Indonesia mengalami pertumbuhan yang signifikan. Berdasarkan data market size dibe- berapa sektor industri di Indonesia (SWA 01/XXIII/Februari 2008) diketahui bahwa restoran fast food mengalami pertumbuhan sebesar 18,1\% pada tahun 2006, 22,1\% pada tahun 2007, dan diperkirakan tahun 2008 mencapai 19,4\%.

Pertumbuhan ini mengindikasikan bahwa restoran fast food memiliki potensi untuk terus dikembangkan khususnya di Indonesia. Hal ini dibuktikan dengan masuknya Indonesia ke dalam 10 besar market global untuk konsumsi fast food

Pengaruh Kinerja Kualitas Pelayanan Melalui Seven Romancing Moments terhadap Pemeblian Ulang pada Restoran Hoka-Hoka Bento Cabang Setiabudi Bandung 


\section{StrategiC}

dalam satu minggu seperti yang disajikan dalam Tabel 1 berikut ini.

Tabel 1

Top 10 Market Global untuk Konsumsi Fast Food (dalam Satu Minggu)

Persentase Populasi Market yang Makan di Restoran Fast Food Minimal Seminggu Sekali

\begin{tabular}{|l|c|}
\hline Hong Kong & $61 \%$ \\
\hline Malaysia & $59 \%$ \\
\hline Filipina & $54 \%$ \\
\hline Singapura & $50 \%$ \\
\hline Thailand & $44 \%$ \\
\hline Cina & $41 \%$ \\
\hline India & $37 \%$ \\
\hline A.S. & $35 \%$ \\
\hline Australia & $30 \%$ \\
\hline Indonesia & $28 \%$ \\
\hline
\end{tabular}

Sumber: ACNielsen Online Consumer Survey, 2007

Menurut hasil riset di atas dapat diketahui bahwa 28\% masyarakat Indonesia mengkonsumsi makan fast food di restoran minimal satu minggu sekali, 33\% diantaranya mengkonsumsi pada saat makan siang, dan akan terus bertambah seiring dengan perkembangan perekonomian di dalam negeri, karena industri restoran merupakan salah satu sektor industri yang dapat menumbuhkan perekonomian daerah serta berpengaruh terhadap pendapatan nasional. Salah satu kota yang memiliki potensi besar dalam sektor restoran fast food adalah Bandung seperti terlihat pada Tabel 2 berikut ini.

Tabel 2

Usaha Restoran Fast Food di Kota/Kabupaten Bandung

\begin{tabular}{|c|c|c|}
\hline \multicolumn{1}{|c|}{ Wilayah } & Tahun & Jumlah Restoran \\
\hline Kota Bandung & 2006 & 61 \\
\hline Kota Bandung & 2007 & 128 \\
\hline Wilayah & Tahun & Jumlah Restoran \\
\hline Kabupaten Bandung & 2006 & 6 \\
\hline Kabupaten Bandung & 2007 & 12 \\
\hline
\end{tabular}

Sumber: DIPARDA Kota Bandung 2007

Tabel 2 menunjukkan bahwa usaha restoran di Kota/Kabupaten Bandung mengalami peningkatan sekitar $50 \%$ sampai dengan $52,3 \%$ selama 2 tahun terakhir sejak tahun 2006. Jumlah restoran yang terus meningkat, telah memberikan kontribusi positif terhadap pendapatan asli daerah Kota/Kabupaten Bandung. DIPENDA Kab. Bandung mencatat sektor restoran merupakan sumber pendapatan urutan pertama dalam pembentukan $P A D$ yang meningkat dari tahun 2006 sebesar 1.839.417.703,73 menjadi 2.380.511.700,80 pada tahun 2007.
Sedangkan menurut Laporan Penyelenggaraan Pemerintah Daerah Kota Bandung 2007 mencatat, kontribusi sektor restoran terhadap PAD Bandung telah melebihi target bahkan cenderung meningkat dari tahun 2006 sebesar 30.741 .746 .438 menjadi $33.000 .964,906,694$ pada tahun 2007 atau mengalami peningkatan $1,93 \%$ dari tahun sebelumnya (Bapeda Kota Bandung).

Restoran yaitu tempat yang berfungsi untuk menyegarkan kembali kondisi seseorang dengan menyediakan kemudahan makan dan minum. Sesuai dengan arti dan fungsi dari suatu restoran harus selalu berusaha memberikan kepuasan kepada pelanggannya. Bisnis fast food telah menjadi lebih kompetitif dengan operator waralaba fast food yang terus memperluas wilayah baru, bersamaan dengan lahirnya pemain baru, jenis masakan baru dan pilihan menu baru. Berikut ini daftar merek fast food yang paling sering dikonsumsi masyarakat Indonesia:

Tabel 3

Merek Fast Food yang Paling Sering Dikonsumsi Masyarakat indonesia

\begin{tabular}{|l|c|}
\hline \multicolumn{1}{|c|}{ Merek } & Bobot \\
\hline KFC & $37 \%$ \\
\hline MC Donalls & $27.5 \%$ \\
\hline Hoka Hoka Bento & $12.5 \%$ \\
\hline A \& W & $4 \%$ \\
\hline Wendy's & $3 \%$ \\
\hline
\end{tabular}

Sumber (Majalah Marketing, 2/V/Feb 2007)

Tabel 3 di atas menunjukan bahwa restoran fast food KFC dan MC Donalls masih menjadi pilihan utama masyarakat Indonesia, akan tetapi diantara maraknya restoran fast food dengan ciri makanan Amerika kini muncul merek Hoka Hoka Bento yang merupakan restoran fast food dengan ciri khas Jepang.

Restoran fast food dengan ciri khas Jepang kini mulai digemari oleh masyarakat, terbukti dengan masuknya Hoka Hoka Bento dalam peringkat ke 3 dari merek fast food yang paling sering digunakan masyarakat Indonesia. Selain itu restoran Jepang lain mulai berkembang di Bandung seperti Gokana, Hanamasa, Miyaki, Hoka Suki, Oki bento dan masih banyak lagi restoran Jepang yang menawarkan keunikan yang beragam.

Bermunculanya restoran fast food Jepang saat ini yang menawarkan konsep berbeda menjadi ancaman bagi Hoka Hoka Bento dalam menjalankan usahanya, seperti restoran Jepang Gokana yang menawarkan sistem by order yaitu 
sistem penyajian sesuai dengan pesanan, Hanamasa yang menerapkan full service, Torigen yang memberikan konsep traditional Japan, maupun restoran-restoran Jepang lainya yang memberikan konsep berbeda dalam memberikan nilai kepada pelanggan.

Persaingan bisnis restoran fast food yang semakin besar membuat Hoka Hoka Bento sulit mengharapkan kesetiaan pelangganya. Pelanggan yang merasa tidak puas akan pelayanan yang diberikan Hoka Hoka Bento akan dengan mudah berpindah pada restoran Jepang lain yang menawarkan nilai yang lebih baik. Hal ini sangat berdampak terhadap jumlah pelanggan Restoran Hoka Hoka Bento yang mengalami penurunan pada awal tahun 2008.

Gambar 1 di bawah ini menyajikan data mengenai rata-rata jumlah customer dine in HokaHoka Bento Tahun 2007-2008.

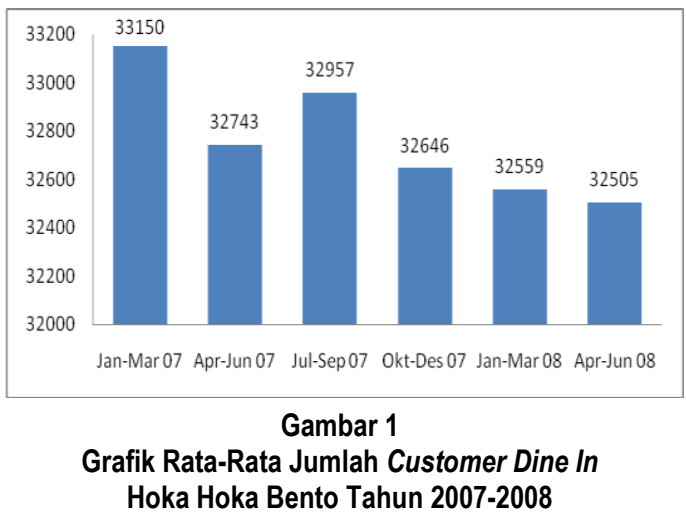

Gambar 1 menunjukan bahwa jumlah pelanggan Hoka Hoka Bento pada bulan Januari hingga Juni tahun 2008 mengalami penurunan dibandingkan bulan yang sama pada tahun 2007 . Penurunan jumlah pelanggan ini akan berdampak pada pendapatan perusahaan serta mempengaruhi kemampuan perusahaan untuk memperoleh keuntungan, dampak jangka panjang yaitu menghambat perkembangan perusahaan, bahkan jika terus menurun maka perusahaan tidak akan mampu lagi mempertahakan posisinya dalam bisnis restoran fast food Jepang.

Diduga fenomena penurunan jumlah pelanggan Hoka Hoka Bento pada awal tahun 2008, disebabkan oleh pelayanan yang diberikan oleh Hoka Hoka Bento. Hal ini dibuktikan dengan data jumlah komplain pelanggan yang disajikan dalam Tabel 4.

\section{StrategiC}

Tabel 4

Jumlah Komplain Pelanggan

\begin{tabular}{|l|l|c|c|}
\hline \multirow{2}{*}{ Jenis komplain } & \multicolumn{3}{|c|}{ Tahun } \\
\cline { 2 - 4 } & $\mathbf{2 0 0 5}$ & $\mathbf{2 0 0 6}$ & $\mathbf{2 0 0 7}$ \\
\hline Komplain terhadap produk & $0,91 \%$ & $0,8 \%$ & $0,7 \%$ \\
\hline Komplain terhadap pelayanan & $1,1 \%$ & $0,92 \%$ & $1,7 \%$ \\
\hline Total & $2,01 \%$ & $1,72 \%$ & $2,4 \%$ \\
\hline
\end{tabular}

Sumber: Kartu Saran Hoka Hoka Bento Cabang Setiabudi

Data di atas menunjukan sebagian besar komplain atau keluhan yang datang berasal dari pelayanan dengan persentase terbesar $1,7 \%$ dari total pelanggan pada tahun 2007 , hal ini sangat berdampak pada kepercayaan, kepuasan pelanggan, yang ingin melakukan pembelian ulang. Pelanggan sebagai pengguna jasa restoran memilih restoran yang mampu memberikan pelayanan sesuai dengan keinginannya. Mereka akan segera meninggalkan dan tidak akan datang kembali ke restoran yang tidak memberikan pelayanan yang sesuai harapannya. Seiring dengan tingkat ekspektasi dan persepsi pelanggan yang semakin meningkatnya persaingan antar restoran, serta terjadinya imitasi produk dan pelayanan, maka Hoka Hoka Bento tidak bisa hanya mengandalkan variasi menu atau sistem service yang biasa, hal tersebut disebabkan oleh semua restoran Jepang memiliki produk dan fasilitas fisik yang tidak jauh berbeda. Sehingga setiap restoran harus menggunakan aspek unique service sebagai alat bersaing yang dapat diandalkan.

Menghadapi persaingan Hoka Hoka Bento dituntut mampu memberikan nilai tambah bagi pelanggan. Salah satu strategi yang dijalankannya yaitu dengan menciptakan keunikan pada produk yang ditawarkan dengan kualitas yang terjaga. Hoka Hoka Bento menawarkan lebih dari 35 jenis makanan yang berbeda dengan cita rasa yang disesuaikan dengan lidah orang Indonesia. Setiap periode Hoka Hoka Bento selalu mengeluarkan produk-produk baru atau paket-paket baru, dan promosi menarik lainya, seperti paket Kidtsu Bento yang menyertakan hadiah berupa mainan Doraemon .

Strategi lain yang dijalankan Hoka Hoka Bento yaitu dengan menerapkan service action yang baru yaitu dengan program layanan seven romancing moments. Program layanan seven romancing moments merupakan saat-saat perjumpaan antara karyawan kontak dengan customer Hoka Hoka Bento pada waktu mereka

Pengaruh Kinerja Kualitas Pelayanan Melalui Seven Romancing Moments terhadap Pemeblian Ulang pada Restoran Hoka-Hoka Bento Cabang Setiabudi Bandung 
menyampaikan layanan pokok Hoka Hoka Bento. Program layanan seven romancing moments diterapkan agar dapat mengelola berbagai macam produk, layanan dan menyajikannya secara menarik sehingga customer akan kembali untuk menikmati kelezatan makanan Hoka Hoka Bento.

Program layanan seven romancing moments terdiri dari ; Irasshaimase, dalam bahasa Indonesia berarti selamat datang, mobile service, pembayaran di kasir, greeting customer di loby, menawarkan dan mengantar menu, take away, arigato gozaimasu. Menjalankan program layanan Seven romancing moments customer harus diikuti dengan 5 sikap service yaitu senyum, menatap customer, suara ramah, pelayanan cepat dan berkomunikasi.

Program layanan seven romancing moments dibuat dalam rangka memperbaiki kualitas pelayanan yang merupakan fungsi dari faktor kelancaran (procedural dimension) dan keramahtamahan petugas terhadap konsumen (conviviality dimension). Upaya tersebut pada dasarnya dilakukan Hoka Hoka Bento untuk menarik konsumen agar melakukan pembelian ulang (repeat purchase).

Pelanggan memilih restoran berdasarkan kebutuhan pribadi dan pengalaman masa lalu setelah menerima jasa, lalu membandingkan harapan akan jasa tersebut dengan jasa yang dirasakan. Bagaimana respon pelanggan terhadap program layanan seven romancing moments itu perlu mendapatkan feed back/evaluasi sehingga apa yang diharapkan dapat sesuai dengan kebutuhan dan keingginan. Berdasarkan latar belakang penelitian di atas maka dirumuskan masalah pokok dalam penelitian ini, yaitu:

1. Bagaimana gambaran kinerja kualitas pelayanan melalui seven romancing moments pada restoran Hoka Hoka Bento Cabang Setiabudi Bandung

2. Bagaimana pembelian ulang pelangan Hoka Hoka Bento Cabang Setiabudi Bandung

3. Seberapa besar pengaruh kinerja kualitas pelayanan melalui seven romancing moments terhadap pembelian ulang pada restoran Hoka Hoka Bento Cabang Setiabudi Bandung

\section{KERANGKA PEMIKIRAN}

Hoka Hoka Bento, sebagai salah satu pelaku bisnis di bidang jasa restoran dengan cirikhas Jepang sangat menyadari perlunya strategi yang diterapkan untuk menghalau pesaing/kompetitor dengan bidang cakupan yang sama. Sebagai perusahaan yang bergerak di bidang jasa restoran, Hoka Hoka Bento menyadari bahwa pelanggan adalah faktor paling penting dalam usaha tersebut.

Perusahaan selain harus mendapatkan pelanggan sebanyak-banyaknya, perusahaan juga harus dapat mempertahankan kesetiaan pelanggannya agar dapat bertahan dalam bisnis ini. Salah satu upaya mempertahankan palanggan yang telah ada dengan menarik pelanggan melakukan pembelian ulang (Kotler and Keller 2009:57).

Program Layanan Seven romancing moments dirancang untuk membentuk loyalitas pelanggan, melalui prilaku pembelian secara berulang. Program ini terdiri dari dimensi 1) Irashaimasse yaitu mengucapkan salam, indikator dari Irashaimasse terdiri dari menyambut tamu, menyapa, memberikan salam dan kerapihan serta kebersihan petugas. 2) Mobile service, indikator dari mobile service terdiri dari menawarkan menu, membantu dalam memilihkan menu, memberikan informasi, melayani dan menyajikan pesanan. 3) Pembayaran di kasir terdiri dari indikator, menghitung umlah pembelian, melakukan transaksi, layanan uang kembali, memberikan bukti pembayaran, dan mengucapkan terima kasih. 4) Greeting customer di loby terdiri dari indikator menawarkan bantuan, membantu tamu, menangani keluhan dan penyediaan kartu saran. 5) Menawarkan dan mengantar menu terdiri dari indikator menawarkan menu pelangkap, memahami kebutuhan pelanggan dan mengantarkan pesanan. 6) Take away terdiri dari indikator menuliskan pesanan, menyampaikan pesanan dan kerapihan dan kualitas menu. 7) Arigato gozaimasu atau menyampaikan ucapan terima kasih.

Konsep dimensi kualitas jasa menurut Parasuraman, Zeithaml, dan Berry, dalam Fandy Tjiptono dan Gregorius Chandra (2005:133), terdapat lima dimensi utama kualitas jasa yang disusun sesuai dengan tingkat kepentingan relatifnya sebagai berikut.

1. Reliabilitas (Reliability)

Reliabilitas berkaitan dengan kemampuan perusahaan untuk memberikan layanan yang akurat sejak pertama kali tanpa membuat kesalahan. 
2. Daya Tanggap (Responssiveness)

Daya tanggap berkenaan dengan kesediaan dan kemampuan para karyawan untuk membantu para pelanggan dan merespons permintaan mereka, serta menginformasikan kapan jasa akan diberikan dan kemudahan memberikan jasa secara cepat.

3. Jaminan (Assurance)

Jaminan yakni perilaku para karyawan mampu menumbuhkan kepercayaan pelanggan terhadap perusahaan dan perusahaan bisa menciptakan rasa aman bagi para pelanggannya.

4. Empati (Empathy)

Empati berarti perusahaan memahami masalah para pelanggannya dan bertindak demi kepentingan pelanggan, serta memberikan perhatian personal kepada para pelanggan dan memiliki jam operasi yang nyaman.

5. Bukti Fisik (Tangibles)

Bukti fisik berkenaan dengan daya tarik fasilitas fisik, perlengkapan, dan material yang digunakan perusahaan serta penampilan karyawan.

Pelanggan memilih penyedia jasa atas kebutuhan pribadi dan pengalaman masa lalu setelah menerima jasa, lalu membandingkan harapan akan jasa tersebut dengan jasa yang dirasakan. Gap antara harapan pelanggan dengan kinerja jasa yang ditawarkan akan selalu terjadi karena harapan pelanggan selalu bergerak naik sedangkan kinerja jasa yang ditawarkan perusahaan sulit mengikuti perubahan tersebut. Penyedia jasa yang menawarkan kualitas layanan paling baik yang akan diterima oleh pelanggan, sesuai dengan kebutuhan dan keinginannya.

Pelanggan yang loyal merupakan aset yang penting bagi perusahaan. Menurut Griffin (2005:31), mengemukakan beberapa karakteristik pelanggan yang loyal sebagai berikut:

1. Makes regular repeat purchases (melakukan pembelian berulang secara teratur);

2. Purchases across product and service lines (membeli di luar lini produk dan jasa);

3. Refers other (mereferensikan kepada orang lain);

4. Demonstrates an immunity to the full of the competition (menunjukan kekebalan terhadap penawaran dari para pesaing).
Pengaruh kualitas pelayanan dalam program layanan seven romancing moments terhadap pembelian ulang dikemukakan oleh Hermawan Kartajaya (2005:97) Kualitas pelayanan yang baik merupakan langkah awal untuk membuat konsumen melakukan pembelian ulang.

Secara teoritis kualitas pelayanan melalui program layanan seven romancing moments yang dilakukan Hoka Hoka Bento berpengaruh pada pembelian ulang pelanggan perusahaan tersebut. Hal ini diperkuat dengan penelitian terdahulu Wisnalmawati (UPN Yogyakarta:2004) dengan judul "Pengaruh persepsi dimensi kualitas layanan terhadap pembelian ulang pada swalayan mirota". Hasil penelitian menunjukkan bahwa variabel persepsi kualitas layanan berpengaruh terhadap pembelian ulang. Variabel persepsi kualitas layanan dan variabel kepuasan secara bersama berpengaruh pada pembelian ulang. Variabel persepsi kualitas layanan berpengaruh pada pembelian ulang melalui kepuasan sebagai variabel moderating pada toko Swalayan Mirota Kampus di Gejayan Yogyakarta

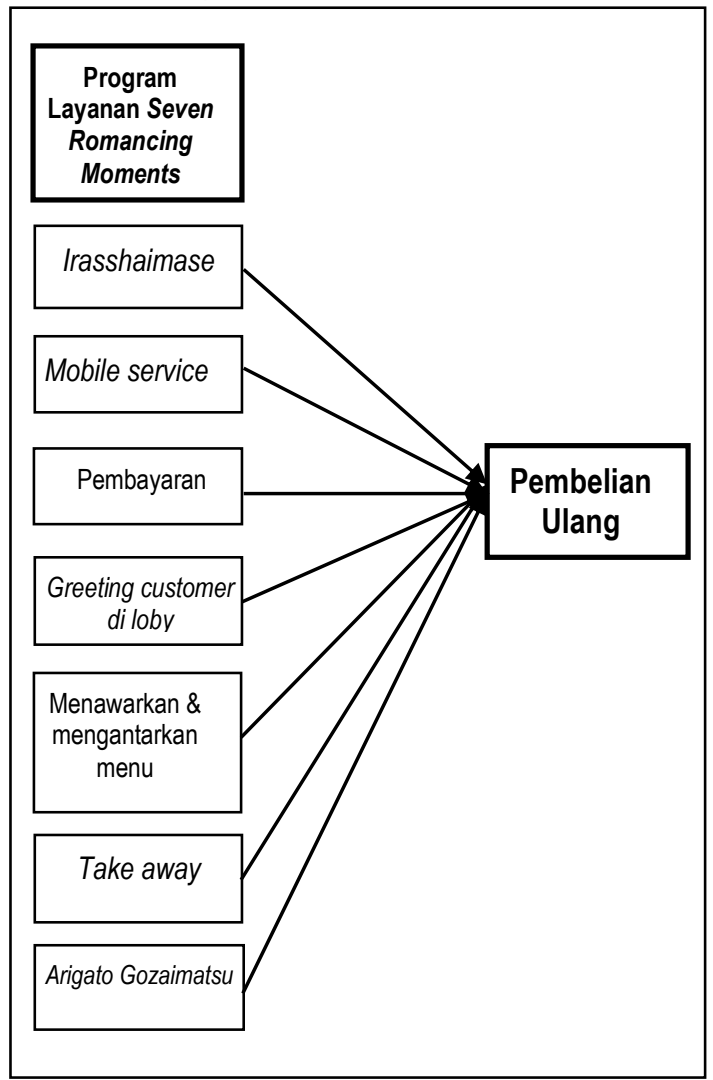

Gambar 2

Paradigma Penelitian 


\section{StrategiC}

\section{METODE PENELITIAN}

Berdasarkan jenisnya, maka penelitian ini bersifat deskriptif dan verifikatif. Melalui penelitian deskriptif akan diperoleh gambaran mengenai program layanan seven romancing moments $(\mathrm{X})$ dengan indikator irasshaimase, mobile service, pembayaran di kasir, greeting customer, menawarkan dan mengantarkan menu, take away, arigato gozaimasu dan pembelian ulang $(Y)$ di restoran Hoka-Hoka Bento Bandung.

Sifat verifikatif pada dasarnya ingin menguji kebenaran dari suatu hipotesis yang dilaksanakan melalui pengumpulan data di lapangan, dimana dalam penelitian ini akan diuji apakah terdapat pengaruh antara kinerja kualitas pelayanan melalui seven romancing moments terhadap pembelian ulang pada restoran Hoka Hoka Bento Bandung.

Berdasarkan jenis penelitiannya, yakni deskriptif dan verifikatif yang dilaksanakan melalui pengumpulan data di lapangan, maka metode penelitian yang akan digunakan adalah metode explanatory survey. Survei informasi dari sebagian populasi (sampel responden) dikumpulkan langsung ditempat kejadian secara empirik, dengan tujuan untuk mengetahui pendapat dari sebagian populasi terhadap objek yang sedang diteliti.

Tabel 5 di bawah ini menyajikan operasionalisasi variabel penelitian.

Tabel 5

Operasionalisasi Variabel

\begin{tabular}{|c|c|c|c|}
\hline $\begin{array}{l}\text { Variabel dan } \\
\text { Sub variabel }\end{array}$ & Indikator & Ukuran & Skala \\
\hline \multicolumn{4}{|l|}{$\begin{array}{l}\text { Kualitas } \\
\text { Pelayanan } \\
\text { melalui } \\
\text { Sevent } \\
\text { Romancing } \\
\text { Moments (x) } \\
\end{array}$} \\
\hline \multirow{3}{*}{$\begin{array}{l}\text { Daya tanggap } \\
\text { (responssiveness) }\end{array}$} & \multicolumn{2}{|r|}{$\begin{array}{c}\text { Irasshaimase } \\
\text { (Greeting) }\end{array}$} & \\
\hline & $\begin{array}{l}\text { Menyambut } \\
\text { tamu }\end{array}$ & $\begin{array}{l}\text { Tingkat Keramahan Petugas } \\
\text { Greeter }\end{array}$ & Ordinal \\
\hline & Menyapa tamu & $\begin{array}{l}\text { Tingkat keramahan petugas } \\
\text { greeter }\end{array}$ & Ordinal \\
\hline \multirow{3}{*}{$\begin{array}{l}\text { Bukti fisik } \\
\text { (tangible) }\end{array}$} & $\begin{array}{l}\text { Memberikan } \\
\text { salam }\end{array}$ & $\begin{array}{l}\text { Tingkat keramahan petugas } \\
\text { greeter saat memberi salam }\end{array}$ & Ordinal \\
\hline & $\begin{array}{l}\text { Kerapihan } \\
\text { petugas greeter }\end{array}$ & $\begin{array}{l}\text { Tingkat Kerapihan petugas } \\
\text { greeter }\end{array}$ & Ordinal \\
\hline & $\begin{array}{l}\text { Kebersihan } \\
\text { petugas greeter }\end{array}$ & $\begin{array}{l}\text { Tingkat kebersihan petugas } \\
\text { greeter }\end{array}$ & Ordinal \\
\hline \multirow{3}{*}{$\begin{array}{l}\text { Reliabilitas } \\
\text { (reliability) }\end{array}$} & \multicolumn{2}{|r|}{ Mobile Service } & \\
\hline & $\begin{array}{l}\text { Menyapa tamu } \\
\text { oleh petugas } \\
\text { counter }\end{array}$ & $\begin{array}{l}\text { Tingkat keramahan petugas } \\
\text { counter saat menyapa tamu }\end{array}$ & Ordinal \\
\hline & $\begin{array}{l}\text { Menawarkan } \\
\text { menu }\end{array}$ & $\begin{array}{l}\text { Tingkat keramahan petugas } \\
\text { counter saat menawarkan } \\
\text { menu }\end{array}$ & Ordinal \\
\hline \multirow[b]{2}{*}{$\begin{array}{l}\text { Daya tanggap } \\
\text { (responsiveness) }\end{array}$} & $\begin{array}{l}\text { Membantu } \\
\text { dalam pemilihan } \\
\text { menu }\end{array}$ & $\begin{array}{l}\text { Tingkat keramahan petugas } \\
\text { counter saat membantu } \\
\text { memilihkan menu }\end{array}$ & Ordinal \\
\hline & $\begin{array}{l}\text { Memberikan } \\
\text { informasi } \\
\text { mengenai } \\
\text { menu/harga }\end{array}$ & $\begin{array}{l}\text { Tingkat ketepatan petugas } \\
\text { dalam menyampaikan } \\
\text { informasi produk/harga } \\
\text { Tingkat kecepatan petugas }\end{array}$ & Ordinal \\
\hline
\end{tabular}

\begin{tabular}{|c|c|c|c|}
\hline $\begin{array}{l}\text { Variabel dan } \\
\text { Sub variabel }\end{array}$ & Indikator & Ukuran & Skala \\
\hline & $\begin{array}{l}\text { Melayani } \\
\text { pesanan }\end{array}$ & $\begin{array}{l}\text { counter dalam melayani } \\
\text { pesanan }\end{array}$ & Ordina \\
\hline & $\begin{array}{l}\text { Menyajikan } \\
\text { pesanan }\end{array}$ & $\begin{array}{l}\text { Tingkat kerapihan menu yang } \\
\text { disajikan petugas counter }\end{array}$ & Ordina \\
\hline \multirow{3}{*}{$\begin{array}{l}\text { Jaminan } \\
\text { (assurance) }\end{array}$} & \multicolumn{2}{|c|}{$\begin{array}{l}\text { Pembayaran di Kasir } \\
\text { (Collect Payment) }\end{array}$} & \\
\hline & $\begin{array}{l}\text { Menghitung } \\
\text { jumlah } \\
\text { pembelian }\end{array}$ & $\begin{array}{l}\text { Tingkat keakuratan petugas } \\
\text { kasir dalam menghitung } \\
\text { pembelian }\end{array}$ & Ordina \\
\hline & $\begin{array}{l}\text { Melakukan } \\
\text { transaksi }\end{array}$ & $\begin{array}{l}\text { Tingkat kecepatan petugas } \\
\text { kasir dalam melakukan } \\
\text { transaksi }\end{array}$ & Ordina \\
\hline \multirow{3}{*}{$\begin{array}{l}\text { Daya tanggap } \\
\text { (responsiveness) }\end{array}$} & $\begin{array}{l}\text { Layanan uang } \\
\text { kembali }\end{array}$ & $\begin{array}{l}\text { Tingkat ketepatan petugas } \\
\text { kasir dalam melayani uang } \\
\text { kembali }\end{array}$ & Ordina \\
\hline & $\begin{array}{l}\text { Memberikan } \\
\text { bukti } \\
\text { pembayaran }\end{array}$ & $\begin{array}{l}\text { Tingkat keramahan petugas } \\
\text { kasir saat Memberikan bukti } \\
\text { pembayaran }\end{array}$ & Ordina \\
\hline & $\begin{array}{l}\text { Mengucapkan } \\
\text { terima kasih dan } \\
\text { selamat makan }\end{array}$ & $\begin{array}{l}\text { Tingkat keramahan petugas } \\
\text { kasir saat mengucapkan } \\
\text { terima kasih dan selamat } \\
\text { makan }\end{array}$ & Ordina \\
\hline \multirow{4}{*}{$\begin{array}{l}\text { Empati } \\
\text { (empathy) } \\
\text { Daya tanggap } \\
\text { (responsiveness) }\end{array}$} & \multicolumn{2}{|c|}{$\begin{array}{l}\text { Greeting Customer } \\
\text { di Loby }\end{array}$} & \\
\hline & $\begin{array}{l}\text { Menawarkan } \\
\text { bantua }\end{array}$ & $\begin{array}{l}\text { Tingkat keramahan petugas } \\
\text { loby saat Menawarkan } \\
\text { bantuan kepada tamu }\end{array}$ & Ordina \\
\hline & Membantu tamu & $\begin{array}{l}\text { Tingkat perhatian petugas } \\
\text { loby saat membantu tamu }\end{array}$ & Ordina \\
\hline & $\begin{array}{l}\text { Menangani } \\
\text { keluahan/ } \\
\text { komplain }\end{array}$ & $\begin{array}{l}\text { Tingkat kecepatan petugas } \\
\text { loby saat menangani } \\
\text { keluhan/komplain }\end{array}$ & Ordina \\
\hline $\begin{array}{l}\text { Jaminan } \\
\text { (assurance) }\end{array}$ & $\begin{array}{l}\text { Penyediaan } \\
\text { kartu saran dan } \\
\text { keritik }\end{array}$ & $\begin{array}{l}\text { Tingkat kemudahan } \\
\text { menyampaikan saran dan } \\
\text { kritik }\end{array}$ & Ordina \\
\hline \multirow{4}{*}{$\begin{array}{l}\text { Daya tanggap } \\
\text { (responsiveness) }\end{array}$} & \multicolumn{2}{|c|}{$\begin{array}{c}\text { Menawarkan dan } \\
\text { mengantarkan menu }\end{array}$} & \\
\hline & $\begin{array}{l}\text { Menawarkan } \\
\text { menu pelangkap }\end{array}$ & $\begin{array}{l}\text { Tingkat keramahan petugas } \\
\text { loby saat menawarkan menu } \\
\text { pelengkap }\end{array}$ & Ordinal \\
\hline & $\begin{array}{l}\text { Memahami } \\
\text { kebutuhan } \\
\text { pelanggan }\end{array}$ & $\begin{array}{l}\text { Tingkat kecermatan petugas } \\
\text { dalam memahami kebutuhan } \\
\text { tamu }\end{array}$ & Ordinal \\
\hline & $\begin{array}{l}\text { Mengantarkan } \\
\text { pesanan }\end{array}$ & $\begin{array}{l}\text { Tingkat ketepatan waktu } \\
\text { pengantaran menu pelengkap } \\
\text { sesuai dengan yang dijanjikan }\end{array}$ & Ordinal \\
\hline \multirow{4}{*}{$\begin{array}{l}\text { Reliabilitas } \\
\text { (reliability) } \\
\text { Daya tanggap } \\
\text { (responsiveness) }\end{array}$} & \multicolumn{2}{|r|}{ Take away } & \\
\hline & $\begin{array}{l}\text { Menuliskan } \\
\text { pesanan }\end{array}$ & $\begin{array}{l}\text { Tingkat Ketepatan Petugas } \\
\text { Delivery Dalam Menuliskan } \\
\text { Pesanan }\end{array}$ & Ordinal \\
\hline & $\begin{array}{l}\text { Pengiriman } \\
\text { pesanan }\end{array}$ & $\begin{array}{l}\text { Tingkat Kecepatan Petugas } \\
\text { Delivery Dalam Pengiriman } \\
\text { Pesanan }\end{array}$ & Ordinal \\
\hline & $\begin{array}{l}\text { Kerapihan dan } \\
\text { kualitas menu } \\
\text { dalam box }\end{array}$ & $\begin{array}{l}\text { Tingkatkualitas dan menu } \\
\text { dalam box }\end{array}$ & Ordinal \\
\hline \multirow{4}{*}{$\begin{array}{l}\text { Empati } \\
\text { (empathy) } \\
\text { Daya tanggap } \\
\text { (responsiveness) }\end{array}$} & \multicolumn{2}{|c|}{ Arigato Gozaimatsu } & \\
\hline & \multirow{3}{*}{$\begin{array}{l}\text { Mengucapkan } \\
\text { terima kasih } \\
\text { oleh para } \\
\text { petugas }\end{array}$} & $\begin{array}{l}\text { Tingkat keramahan petugas } \\
\text { greeter saat mengucapkan } \\
\text { terima kasik }\end{array}$ & Ordinal \\
\hline & & $\begin{array}{l}\text { Tingkat keramahan petugas } \\
\text { counter saat mengucapkan } \\
\text { terima kasik }\end{array}$ & Ordinal \\
\hline & & $\begin{array}{l}\text { Tingkat keramahan petugas } \\
\text { loby saat mengucapkan terima } \\
\text { kasik }\end{array}$ & Ordinal \\
\hline \multirow[t]{4}{*}{$\begin{array}{l}\text { Pembelian } \\
\text { Ulang }(Y)\end{array}$} & & & \\
\hline & $\begin{array}{l}\text { Kepuasan } \\
\text { konsumen }\end{array}$ & Tingkat kepuasan konsumen & Ordina \\
\hline & $\begin{array}{l}\text { Melakukan } \\
\text { pembelian }\end{array}$ & $\begin{array}{l}\text { Frekuensi pelanggan dalam } \\
\text { melakukan pembelian }\end{array}$ & Interva \\
\hline & $\begin{array}{l}\text { Pembelian } \\
\text { yang bertambah }\end{array}$ & $\begin{array}{l}\text { Frekuensi jumlah pembelian } \\
\text { yang semakin bertambah }\end{array}$ & Interva \\
\hline
\end{tabular}

Sumber : Hasil Pengolahan Dari Berbagai Sumber

Strategic, Volume 8, Nomor 16, September 2009 


\section{StrategiC}

\section{HASIL PENELITIAN DAN PEMBAHASAN}

Pengujian hipotesis dilakukan untuk menguji besarnya pengaruh program layanan seven romancing moments $(X)$ yang terdiri dari Irasshaimase $\left(X_{1}\right)$, mobile service $\left(X_{2}\right)$, pembayaran di kasir $\left(X_{3}\right)$, greeting customer di loby $\left(X_{4}\right)$, menawarkan dan mengantarkan menu $\left(X_{5}\right)$, take away $\left(X_{6}\right)$, arigato gozaimatsu $\left(X_{7}\right)$ dan pembelian ulang $(Y)$. Hasil korelasi antara program layanan seven romancing moments dan pembelian ulang disajikan dalam Tabel 19 di bawah ini.

Tabel 19

Matrik Korelasi antara Dimensi Program Layanan Seven Romancing Moments Dengan Pembelian Ulang

\begin{tabular}{|c|r|r|r|r|r|r|r|r|}
\hline & \multicolumn{1}{|c|}{$\mathbf{Y}$} & $\mathbf{X}_{1}$ & $\mathbf{X}_{\mathbf{2}}$ & $\mathbf{X}_{\mathbf{3}}$ & $\mathbf{X}_{\mathbf{4}}$ & $\mathbf{X}_{\mathbf{5}}$ & $\mathbf{X}_{\mathbf{6}}$ & $\mathbf{X}_{\mathbf{7}}$ \\
\hline $\mathbf{Y}$ & 1.000 & .058 & .532 & .203 & .449 & .518 & .090 & .333 \\
\hline $\mathbf{X}_{\mathbf{1}}$ & .058 & 1.000 & .326 & .328 & .296 & .103 & .108 & .062 \\
\hline $\mathbf{X}_{\mathbf{2}}$ & .532 & .326 & 1.000 & .269 & .313 & .361 & .119 & .165 \\
\hline $\mathbf{X}_{\mathbf{3}}$ & .203 & .328 & .269 & 1.000 & .050 & .070 & .046 & .126 \\
\hline $\mathbf{X}_{4}$ & .449 & .296 & .313 & .050 & 1.000 & .452 & .128 & .209 \\
\hline $\mathbf{X}_{5}$ & .518 & .103 & .361 & .070 & .452 & 1.000 & .030 & .117 \\
\hline $\mathbf{X}_{6}$ & .090 & .108 & .119 & .046 & .128 & .030 & 1.000 & .019 \\
\hline $\mathbf{X}_{\mathbf{7}}$ & .333 & .062 & .165 & .126 & .209 & .117 & .019 & 1.000 \\
\hline
\end{tabular}

Sumber: Hasil pengolahan Data 2008
Bento. Kegiatan pelanggan memilih dan memesan makanan serta pelayanan petugas saat menawarkan dan menyajikan makanan merupakan suatu kesatuan yang mempengaruhi penilaian pelanggan dalam melakukan pembelian ulang. Sedangkan yang memiliki nilai korelasi terendah yaitu Irasshaimase $(0,058)$, kegiatan ini mencakup menyambut tamu oleh petugas serta kemenarikan dan kerapihan pakaian petugas.

Berdasarkan hasil korelasi selanjutnya akan dilakukan uji $\mathrm{F}$ untuk mengetahui hasil hipotesis. Besarnya nilai korelasi di atas dibuktikan dengan penolakan $\mathrm{Ho}$ yang dilakukan dengan uji $\mathrm{F}$ tingkat signifikan (sig) sama dengan 0,000. atau lebih kecil dari 0,05 .

Pengaruh langsung dan tidak langsung antara dimensi variabel yang diteliti disajikan dalam Tabel 20. Hasil pengujian koefisien jalur menunjukan bahwa nilai $t$ hitung lebih besar dari pada $t$ table seperti yang disajikan pada table $4.30 \mathrm{~d}$ iatas. Hal ini berarti hipotesis yang diajukan "tidak terdapat pengaruh yang positif antara program layanan seven romancing moments terhadap pembelian ulang pada restoran Hoka Hoka Bento cabang Setiabudi Bandung" ditolak.

Tabel 20

Hasil Pengujian Koefisien Jalur Pengaruh Langsung dan Tidak Langsung Dimensi Variabel $X$ terhadap $Y$

\begin{tabular}{|c|c|c|c|c|c|c|c|c|c|c|c|c|}
\hline \multirow{2}{*}{$X$} & \multirow{2}{*}{$\begin{array}{c}\text { Pengaruh } \\
\text { Langsung } \\
\text { Terhadap } \\
\text { Y }\end{array}$} & \multicolumn{7}{|c|}{ Pengaruh Tidak Langsung } & \multirow{2}{*}{$\begin{array}{c}\text { Total } \\
\text { Pengaruh }\end{array}$} & \multirow{2}{*}{$\begin{array}{c}t \text { tabel } \\
1,988 \\
t \text { hitung } \\
\end{array}$} & \multirow{2}{*}{$\begin{array}{c}\text { Sign } \\
\text { Alpha } \\
0,05\end{array}$} & \multirow{2}{*}{$\begin{array}{l}\text { Kepu- } \\
\text { tusan }\end{array}$} \\
\hline & & $X_{1}$ & $\mathbf{X}_{2}$ & $\mathbf{X}_{3}$ & $X_{4}$ & $X_{5}$ & $X_{6}$ & $X_{7}$ & & & & \\
\hline $\mathrm{X} 1$ & 0,048 & - & 0,026 & 0,013 & 0,016 & 0,007 & 0,036 & 0,024 & 0,122 & 2,746 & 0,007 & Ho Ditolak \\
\hline $\mathrm{X} 2$ & 0,130 & 0,026 & - & 0,018 & 0,113 & 0,038 & 0,007 & 0,017 & 0,219 & 4,377 & 0,000 & Ho Ditolak \\
\hline $\mathrm{X} 3$ & 0,033 & 0,013 & 0,018 & & 0,005 & 0,004 & 0,002 & 0,005 & 0,047 & 2,357 & 0,021 & Ho Ditolak \\
\hline $\mathrm{X} 4$ & 0,065 & 0,016 & 0,113 & 0,005 & & 0,035 & 0,005 & 0,015 & 0,189 & 3,017 & 0,003 & Ho Ditolak \\
\hline $\mathrm{X} 5$ & 0,083 & 0,006 & 0,038 & 0,004 & 0,035 & & 0,004 & 0,006 & 0,093 & 3,487 & 0,001 & Ho Ditolak \\
\hline $\mathrm{X} 6$ & 0,024 & 0,036 & 0,004 & 0,007 & 0,005 & $0, \overline{004}$ & & 0,005 & 0,061 & 2,174 & 0,032 & Ho Ditolak \\
\hline $\mathrm{X} 7$ & 0,033 & 0,024 & 0,017 & 0,005 & 0,015 & 0,006 & 0,005 & & 0,072 & 2,500 & 0,014 & Ho Ditolak \\
\hline & & & & & & & & & $R^{2}=0,793$ & & & \\
\hline
\end{tabular}

Sumber: Hasil Pengolahan Data 2008

Berdasarkan hasil matrik korelasi dimensidimensi antara program layanan seven romancing moments terhadap pembelian ulang seperti yang disajikan pada Tabel 19, diperoleh hasil korelasi secara berurutan yaitu: Mobile service $(0,532)$; Menawarkan dan mengantarkan menu $(0,518)$; Greeting customer di loby $(0,449)$; Arigato gozaimatsu $(0,333)$; Pembayaran di kasir $(0,203)$; Take Away $(0,090)$; dan Irasshaimase $(0,058)$.

Mobile service memperoleh korelasi terbesar hal ini terjadi karena mobile service merupakan inti dari kegiatan pelayanan yang ada di Hoka Hoka
Besarnya pengaruh langsung pada pembelian ulang, menunjukan mobile service memiliki pengaruh yang lebih tinggi dibandingkan dengan dimensi-dimensi lain yaitu sebesar $13 \%$. Sedangkan pengaruh tidak langsung antara mobile service dan greeting customer di loby sebesar $11,3 \%$, dan pengaruh tidak langsung antara mobile service dan menawarkan dan mengantarkan menu sebesar $3,8 \%$. Total pengaruh mobile service secara langsung dan tidak langsung sebesar $21,9 \%$. 
Penolakan terhadap hipotesis didukung dengan fakta yang ada di lapangan bahwa Hoka Hoka Bento merancang program ini dengan dasar need and want dari pelanggan, banyaknya menu serupa yang ditawarkan restoran Jepang lainnya membuat Hoka Hoka Bento merasa tidak cukup hanya dengan menjaga kualitas peroduk dan menambah variasi menu, salah satu faktor yang membedakan Hoka Hoka Bento dengan restoran Jepang lain adalah kualitas layanan terhadap pelangganya melalui program layanan seven romancing moments.

Adrian Payne (2004:121) mengemukakan bahwa: "Perusahaan jasa harus berfokus secara khusus pada layanan pelanggan dan mempertahankan tingkat kepuasan pelanggan berdasarkan kajian yang berkesinambungan. Perusahaan jasa harus terus beradaptasi dengan kebutuhan pelanggan yang selalu berubah dalam hal layanan pelanggan."

Kotler dan Armstrong (2008:34) menyatakan bahwa jika pelanggan merasa puas terhadap kinerja produk maka mereka akan melakukan pembelian ulang dengan melakukan pemanfaatan produk berulang-ulang, bahkan lebih jauh lagi, mereka akan melakukan promosi dari mulut ke mulut kepada orang lain. Maka setiap perusahaan harus mempunyai keunggulan dalam bersaing.

Berdasarkan hasil perhitungan di atas dapat diketahui bahwa pengaruh program layanan seven romancing moments terhadap pembelian ulang adalah sebesar 0,793 sedangkan koefisien jalur variabel lain di luar variabel program layanan seven romancing moments dengan dimensi Irasshaimase, mobile service, pembayaran di kasir, greeting customer di loby, menawarkan dan mengantarkan menu, take away, arigato gozaimatsu ditentukan dengan rumus:

$$
\begin{aligned}
& P_{Z \varepsilon}=\sqrt{1-R^{2}{ }_{Y(X 1.1, X 1.2 \ldots X 1.7)}} \\
= & \sqrt{1-0.793} \\
= & 0,455
\end{aligned}
$$

Hal tersebut berarti bahwa $X_{1}$ sampai dengan $X_{7}$ bersama-sama mempengaruhi pembelian ulang pelanggan Hoka Hoka Bento sebesar 79,3\% dan sisanya sebesar $(0,455)^{2}=0,207 \times 100 \%=20,7 \%$ dipengaruhi oleh variabel lain yang tidak termasuk dalam penelitian ini seperti promosi melalui periklanan, karena Hoka Hoka Bento jarang mempromosikan produknya di media cetak maupun elektronik kecuali jika ada produk-produk baru.

Adapun pengaruh kualitas pelayanan dalam program layanan seven romancing moments terhadap pembelian ulang dikemukakan oleh Hermawan Kartajaya (2005:97) Kualitas pelayanan yang baik merupakan langkah awal untuk membuat konsumen melakukan pembelian ulang. (Kotler\&Keller 2009:57) menyatakan bahwa " Salah satu upaya mempertahankan palanggan yang telah ada adalah dengan menarik pelanggan melakukan pembelian ulang.

Hal ini diperkuat dengan penelitian terdahulu Wisnalmawati (UPN Yogyakarta:2004) dengan judul "Pengaruh persepsi dimensi kualitas layanan terhadap pembelian ulang pada swalayan mirota". Hasil penelitian menunjukkan bahwa variabel persepsi kualitas layanan berpengaruh terhadap pembelian ulang. Variabel Persepsi kualitas layanan dan variabel kepuasan secara bersama berpengaruh pada pembelian ulang. Variabel persepsi kualitas layanan berpengaruh pada pembelian ulang pada toko Swalayan Mirota Kampus di Gejayan Yogyakarta

\section{IMPLIKASI HASIL TEMUAN PENELITIAN}

\section{Temuan yang Bersifat Empirik}

1. Program layanan seven romancing merupakan serangkaian tindakan nyata yang dilakukan Hoka Hoka Bento dalam menyampaikan layanan pokok dari mulai tamu datang sampai dengan meninggalkan restoran, program tersebut meliputi Irasshaimase, mobile service, pembayaran di kasir, greeting customer di loby, menawarkan dan mengantarkan menu, take away, arigato gozaimatsu. Dari faktor-faktor pembentuk tersebut mobile service merupakan faktor yang paling tinggi dalam menentukan pembelian ulang pelanggan Hoka Hoka Bento cabang Setiabudi Bandung.

2. Faktor pembentuk pembelian ulang pelanggan Hoka Hoka Bento cabang Setiabudi Bandung yang memiliki nilai yang paling tinggi yaitu kepuasan, untuk menciptakan kepuasan bagi pelanggan tidak cukup hanya faktor kelancaran saja akan tetapi dibutuhkan keramahtamahan petugas. Konsumen yang merasa puas terhadap produk atau merek yang dikonsumsi 
atau dipakai akan membeli ulang produk tersebut

\section{Temuan yang Bersifat Teoritik}

1. Berdasarkan hasil temuan penelitian penulis melakukan modifikasi konsep program layanan seven romancig moments menggunakan konsep dimensi kualitas pelayanan, menurut Fandy Tjiptono dan Gregorius Chandra (2005:133) terdiri dari: Irasshaimase berkenaan dengan tangibles (tampilan fasilitas fisik, peralatan, karyawan, dan bahan-bahan promosi) dan responsiveness (kesediaan untuk membantu konsumen dan menyampaikan pelayanan secara cepat dan tepat terkait dengan permintaan, kesulitan, dan keluhan konsumen); Mobile service berkenaan dengan reability (kemampuan untuk memenuhi janji) dan responsiveness (kesediaan untuk membantu konsumen dan menyampaikan pelayanan secara cepat dan tepat terkait dengan permintaan, kesulitan, dan keluhan konsumen); Pembayaran di kasir berkenaan dengan assurance (jaminan) dan responsiveness; Greeting customer di loby berkenaan dengan empathy (perhatian), assurance (jaminan) dan responsiveness; Menawarkan dan mengantarkan menu berkenaan dengan assurance (jaminan) dan responsivenes; Take away berkenaan dengan reability (kemampuan untuk memenuhi janji) dan responsiveness (kesediaan untuk membantu konsumen dan menyampaikan pelayanan secara cepat dan tepat terkait dengan permintaan, kesulitan, dan keluhan konsumen); Arigato Gozaimatsu berkenaan dengan empathy (perhatian) dan responsiveness

2. Berdasarakan hasil temuan penelitian penulis memodifikasi konsep Lewis \& Booms, dalam Fandy Tjiptono dan Gregorius Chandra (2005:121), oliver (1981 dalam Djati, 2004) bahwa Kualitas pelayanan sebagai ukuran seberapa bagus tingkat layanan yang diberikan mampu sesuai dengan ekspektasi pelanggan dan menghubungkan kepuasan pelanggan terhadap perilaku pembelian ulang dan loyalitas pelanggan adalah yang paling sering digunakan sebagai referensi

Berdasarkan temuan-temuan tersebut, maka diyakini hasil penelitian ini mampu memberikan sumbangan ilmiah bagi pengembangan ilmu manajemen pemasaran khususnya kualitas pelayanan dan pembelian ulang dan juga sebagai masukan yang konstruktif dan inspiratif bagi perusahaan yang bergerak pada bidang restoran.

\section{SIMPULAN DAN SARAN}

Simpulan

Berdasarkan hasil penelitian yang telah dilakukan dengan menggunakan analisa deskriptif dan verifikatif antara program layanan seven romancing moments terhadap pembelian ulang pada Hoka Hoka Bento cabang Setiabudi Bandung dapat diambil simpulan sebagai berikut.

1. Program layanan seven romancing moments yang terdiri dari Irasshaimase mobile service, pembayaran di kasir, greeting customer di loby, menawarkan dan mengantarkan menu, take away, serta arigato gozaimatsu, secara umum pengunjung memiliki penilaian yang tinggi terhadap program ini. Program layanan seven romancing moments yang paling tinggi penggarunya terhadap pembelian ulang adalah melalui mobile service.

2. Gambaran pengunjung mengenai pembelian ulang pada restoran Hoka Hoka Bento cabang Setiabudi Bandung secara umum cukup tinggi. Aspek yang memiliki nilai tertinggi adalah kepuasan terhadap pelayanan.

3. Program layanan seven romancing moments mempunyai pengaruh yang tinggi terhadap pembelian ulang. Hal tersebut menunjukkan bahwa pelaksanaan Program layanan seven romancing moments yang dilakukan Hoka Hoka Bento melalui Irasshaimase mobile service, pembayaran di kasir, greeting customer di loby, menawarkan dan mengantarkan menu, take away, serta arigato gozaimatsu mampu mempengaruhi pembelian ulang pada restoran Hoka Hoka Bento cabang Setiabudi Bandung.

\section{Saran}

Berdasarkan hasil penelitian yang dilakukan, maka penulis memberikan saran sebagai berikut:

1. Program layanan seven romancing moments terbukti mampu mempengaruhi pembelian ulang, akan tetapi ada beberapa unsur didalamnya yang harus diperbaiki, seperti pembayaran di kasir. Pada saat waktu

Pengaruh Kinerja Kualitas Pelayanan Melalui Seven Romancing Moments terhadap Pemeblian Ulang pada Restoran Hoka-Hoka Bento Cabang Setiabudi Bandung 
kunjungan ramai sering kali terjadi antrian panjang pada saat akan melakukan pembayaran di kasir hal ini dapat diantisipasi dengan memperbaiki petugas kasir yang ada melalui berbagai pelatihan atau traning agar lebih akurat dan cepat pada saat melakukan transaksi. Solusi lainnya yaitu dengan memisahkan tempat kasir untuk pelanggan dine in dan pelanggan take orderltake away.

2. Permasalahan lain yang harus diperhatikan yaitu masalah ketepatan pengantaran menu sesuai dengan waktu yang dijanjikan, hal ini dapat diperbaiki dengan mempercepat proses order taking dari pelayanan yang diberikan sehingga pelanggan tidak perlu menunggu lama untuk mendapatkan makanannya dengan cara meninjau cara kerja karyawan dan sistem kerja/alur kerja pelayanan. Solusi lain yaitu dengan menyediakan jam pasir, sehingga waktu yang digunakan untuk melayani satu pelanggan dapat terukur dengan baik, dan apabila waktu yang digunakan lebih dari jam pasir maka pelanggan berhak mendapatkan reward berupa potongan harga maupun free drink.

3. Saran penulis berdasarkan hasil penelitian untuk meningkatkan pembelian ulang pada restoran Hoka Hoka Bento adalah dengan membuat suatu program khusus untuk mengikat para pengunjung agar dapat merasakan keuntungan dan perhatian. Salah satunya dengan diadakan program member club atau kartu pelanggan. Keuntungan yang diperoleh Hoka Hoka Bento dengan program ini selain dapat meningkatkan pembelian ulang dan akan menciptakan loyalitas pelanggan juga dapat menambah pelanggan baru dan meningkatkan serta menanamkan citra baik perusahaan di mata pelanggannya.

4. Hoka Hoka Bento harus meningkatkan kualitas pelayanan pada dimensi reliabilitas di mana keandalan karyawan untuk menepati janji pelayanan yang diberikan akan selalu terpenuhi, oleh karena itu perlu diadakan pelatihan karyawan Hoka Hoka Bento agar karyawan lebih cekatan dalam melayani tamu. Jika karyawan terlatih dengan baik maka akan memperlancar operating system pelayanan yang diberikan. Selain itu sebaiknya Hoka Hoka Bento terus menambah variasi menu baru tiap bulannya dengan menambah jenis paket yang sesuai dengan keinginan pelanggan.

\section{DAFTAR PUSTAKA}

Aaker, David A. 2004. Marketing Research 8th Edition. New Jersey: John Willey \& Sons Inc.

Asep Hermawan. 2006. Penelitian Bisnis Paradigma Kuantitatif. Jakarta: PT. Gramedia Widia Sarana Indonesia.

Bilson Simamora. 2003. Panduan Riset Perilaku Konsumen. Jakarta, PT Gramedia Pustaka Umum.

Buchari Alma. 2004. Manajemen Pemasaran dan Pemasaran Jasa. Bandung: CV. Alfabeta.

Chandra, Gregorius, Fandy Tjiptono, Dadi Adriana, 2008. Mengupas Topik Utama Pemasaran Strategik, Branding Strategy, Customer Satisfaction, Strategi Kompetitif, Hingga eMarketing. Yogyakarta: Andi.

Crown Dirgantoro. 2003. Value Based Management, Paradigma Sukses Usaha. PT. Gramedia, Jakarta.

Djaslim Saladin. 2003. Intisari Pemasaran dan Unsur-unsur Pemasaran. Bandung: Linda Karya.

Fandy Tjiptono. 2005. Pemasaran Jasa. Malang: Bayumedia Publishing.

Griffin, Ricky W. \& Ronald J. Ebert. 2006. Business, $8^{\text {th }}$ Edition New Jersey: Pearson International Edition.

Husein Umar. 2003. Metode Riset Bisnis. Jakarta: PT Gramedia Pustaka Utama, Jakarta.

Kotler, Phillip and Garry Amstrong. 2006. Principles of Marketing $11^{\text {th }}$ Edition. New Jersey: Prentice Hall Pearson International.

Kotler, Phillip and Kevin L. Keller. 2006. Marketing Management, $12^{\text {th }}$ Edition Pearson International Edition. New Jersey: Prentice Hall.

Kotler, Phillip. 2005. Manajemen Pemasaran Edisi Kesebelas. Jilid 1. Jakarta: PT. INDEKS Kelompok Gramedia.

Kotler, Phillip. 2005. Manajemen Pemasaran Edisi Kesebelas. Jilid 2. Jakarta: PT. INDEKS Kelompok Gramedia.

Levy and Weithz. 2001. Retailing Management. Boston: Mc.Graw.Hill,Irwin.

Lovelock, Christopher and Jochen W. 2007. Manajemen Pemasaran Jasa. Jakarta: Indeks.

Lupiyoadi, Rambat, A. Hamdoni. 2006. Manajemen Pemasaran Jasa. Jakarta: Salemba Empat.

R. Ibrahim. 2002. Kurikulum dan Pembelajaran. Bandung: FPIP UPI. 
Schiffman, Leon.G. dan Kanuk, Leslie. 2003. Consumer Behavior. Jakarta: Prentice Hall Internasionallnc.

Setiadi, J. Nugroho. 2004. Perilaku Konsumen. Jakarta: Prenada.

Sugiyono, 2006. Metode Penelitian Bisnis. Alfabeta, Bandung.

Suharsimi Arikunto, 2006. Prosedur Penelitian Suatu Pendekatan Praktis. Jakarta: Rineka Cipta.

Susanto A.B and Wijanarko Himawan. 2004. Power Branding (Membangun Merek Unggul dan Organisasi Pendukungnya). Jakarta: PT Mizan Publika.

Swastha Basu DH. dan Irawan. 2005. Manajemen Pemasaran Modern. Yogyakarta Penerbit Liberty.

Teguh Budiarto. 1993. Dasar Pemasaran. Jakarta: Guna Darma.

Ulber Silalahi. 2006. Metode Penelitian Sosial. Bandung: Universitas Parahyangan Press.

Yazid. 2005. Pemasaran Jasa: Konsep dan Implementasi. Yogyakarta: Ekonisia Kampus FE UII.

Zeithaml, Valerie A. and Mary Jo Bitner. 2006. Service Marketing Integrating Customer Focus Across The Firm. New Jersey: Prentice Hall International, Inc.

Jurnal

Ady Mahendra dan Haikal Wirawan. "Menciptakan Hubungan Jangka Panjang dengan Konsumen Industri Seluler di Indonesia Saat Perang Tarif Murah". (1 september 2006).

Aryo Daru Driyo. 2006. "Artikel Prospek Bisnis Telekomunikasi Di Indonesia". Ecomonic Review No 204 Juni 2006

Isman Pepadri. 2002. "Pricing is The Moment Of Truth All Marketing Comes To Focus In The Pricing Decision". Usahawan NO. 10 TH XXXI Oktober 2002.

Mastel. 2008. "Seminar Regulasi Tarif Telekomunikasi Indonesia". (24 maret 2008).

Pa Desofa. 2008. "Pendidikan Sebagai Konsumsi dan Investasi Ekonomi". (28 january 2008).

Pengaruh Kinerja Kualitas Pelayanan Melalui Seven Romancing Moments terhadap Pemeblian Ulang pada Restoran Hoka-Hoka Bento Cabang Setiabudi Bandung 